\title{
A Study on Gender Differences in Speech Act of Refusal of Chinese College Students
}

\author{
Hao Liu', a and Mengyu Qian 2,b* \\ Nanjing University of Finance and Economics, Nanjing, Jiangsu, China \\ a liuhaoleo@163.com, b522071873@qq.com
}

Keywords: Gender differences; Refusal strategy; Speech act; College students

\begin{abstract}
In our daily life, gender difference usually causes problems and conflicts in the conversations between male and female, therefore, in the intercultural communication, inter-gender communication is a topic that experts and scholars pay much attention to. Through exploring the gender differences of Chinese college students' speech act of refusal, the paper aims to help people know more about themselves and others' communication styles, and to make the cross-gender communication proceeds more smoothly and effectively. This paper adopts methods of questionnaire and interview, analyzing the differences between male and female college students in the selection of refusal strategy in different situations, while involving some external factors' influence on male and female students' refusal strategy. The research finds that both of male and female students tend to use indirect refusal strategies, and different refusal strategies are used when students faces different initiating acts, but female students are more indirect and polite generally.
\end{abstract}

\section{Introduction}

\section{Research Background}

Speech act theory was firstly put forward by Austin(1962) and developed by Searle (1975), and it has become an important issue in the research of modern pragmatics. Refusal is a common speech act in our daily life. Refusal means saying no to a request, suggestion, invitation or offer, which is negative to the interlocutor who requests, suggests, invites, or offers something. The form and content of the speech act of refusal can be influenced by many factors, such as gender, age, social status and power distance.

Gender difference usually causes problems and conflicts in daily conversations between male and female. In the situation of refusal, they may also choose different ways. The research merely on the speech act of refusal or gender difference have been done previously, however, little attention is given to the gender difference on students' speech act of refusal. Therefore, gender is an important factor which is worthy studying and it is necessary to explore how and why male and female differ in their speech act of refusal so as to better understand their thinking modes and communicative habits.

\section{Purpose and Significance}

The present study uses the methods of questionnaire and interview to examine male and female students' speech act of refusal in different situations. The paper's purpose is to explore whether there are differences between male and female students' speech act of refusal and what the internal causes are. The significance of this paper is that through analyzing the gender differences in Chinese college students' speech act of refusal, the paper can help male and female know more about themselves and each other, then promote the cross-gender communication in our daily life.

\section{Global Structure}

This paper begins with a brief introduction. The second part provides an overview of previous studies on refusal and gender difference, followed by the introduction and related research on the theoretical basis: Speech Act Theory. Then the methodology that the present study uses is introduced in the third part, including qualitative study and quantitative study. In the fourth part, the data and the result of the survey are analyzed and discussed, followed by the analysis on the internal causes for the result. Finally, the last part provides a conclusion, which includes a summary, 
limitations of the paper and suggestions for future studies.

\section{Literature Review}

\section{Previous Researches on Refusal}

Researches Abroad

The speech act of refusal in foreign country is studied from the perspectives of syntax, sociolinguistics, pragmatics, and second-language acquisition. However, with the development of Intercultural Communication, many comparative studies on speech act of refusal have been achieved.

Among these studies of refusal, Beebe, Takahashi and Uliss-Weltz's research(1990) is very influential and valuable in terms of the classification system of semantic formulas and the design of questionnaire, which are still employed by many subsequent studies. They compare refusals given by native speakers of English and native speakers of Japanese, adopting the method of Discourse Completion Test consisting of 12 situations, which can be classified into the situations of request, invitation, suggestion and offer [1]. Liao and Bresnahan(1996) make a comparative study between Mandarin and American English on refusal strategies by asking Taiwanese and American university students to fill in six situations of requests[2]. In Okura's research, the interlanguage research on refusal was narrowed down into refusing one specific speech act, invitation. Okura firstly investigated how the Japanese language and socio-cultural values affect production of the speech act, and secondly an oral DCT was adopted as the method of data collection.

With regard to gender differences, Garcia (1992) compared the speech act performance in refusals for invitation of two groups, male and female native speakers of Peruvian Spanish. He proposed that insistence was expected in this Peruvian socio-cultural setting[3].

Researches at Home

Chinese scholars were inspired by those foreign studies, and they realized that the speech act of refusal is a topic that should attract more and more studies.

Yao Jun(2003) adopted Liao\&Bresnahan's questionnaire and classification of refusal strategies and compared refusal strategies used by mainland Chinese and American college students. He detected a typical order of strategies used by Chinese subjects when refusing a higher-status interlocutor: address form + regret + reason. Besides, Ma Yuelan(2000) has classified the common refusal strategies in Americans and Chinese. Wu Jianshe(2003) has classified various expressions of refusals at the level of sentence and context. Bi Jiwan(1996) summed up the findings made by B.M.Beebe., and he found out the findings are also appropriate in Chinese people.

All in all, there are some linguists that have carried out their research on refusal strategies, but there are fewer studies concerning gender differences, especially on Chinese college students. Therefore, this paper will concentrate on the study of refusal on gender difference among Chinese male and female college students.

\section{Previous Researches on Gender Differences}

\section{Researches Abroad}

Gender affects people when they use language in social context. Many scholars on sociolinguistics have made efforts to explain the gender-based differences in language use. Three approaches on gender research are most influential and significant: dominance approach, difference approach, and social constructionist approach.

By dominance approach, Robin Lakoff (1975) thinks there exists a bunch of features that distinguish the speech of women from the speech of men, and the reason for females are more polite than males in speech act is the result of the gender-inequality[4]. The difference theory assumes that women and men use specific and special verbal strategies and communicative styles, which are developed in same-sex child peer groups. By difference approach, Maltz and Borker put forward the lists of "women' s features" and "men' s features"[5]. And in the work You Just Don't Understand (1990), Deborah Tannen holds that cross-cultural communication can be difficult because of the big difference in language use, but people can make efforts to minimize the misunderstandings[6]. Social Constructionist Approach treats gender as a social construct, and gender exists not only in 
persons but also in transactions. Mary Crawford conceptualizes gender as a system operating at three levels, including the social structural level, the interpersonal level and the individual level[7]. Julia T. Wood's work Gendered Lives demonstrates the multiple and often interactive ways that our views of masculinity and femininity are shaped within contemporary culture. Research in this paper is mainly based on difference approach, which analyzes male and female subjects' differences.

Researches at Home

The studies on linguistic gender difference in China have not developed as well as in Western countries, and the research in this field is at the preliminary period. Zhao Yuanren is the first scholar who carries out studies on gender differences in China. He points that there are some potential gender differences in phonetics and tones[8]. In the 1980s, lots of accomplishments are made in introduction and analytic comparison of male and female languages in English. In addition, Yao Yaping's paper Cross-Gender Communication: Theories and Approaches and Hu Mingyang's survey on female pronunciation of Mandarin Chinese have contributed to the research on gender differences in China.

These studies paved the way for subsequent exploration into gender-related differences in Chinese, but they seldom use the method of experimental studies, which are considered as more scientific and systematic methods in surveying the gender differences in language. This paper will employ questionnaire investigation to observe the gender differences between Chinese male and female college students when they perform speech act of refusals.

\section{Speech Act Theory}

Refusal is a speech act, so it is necessary to put forward speech act theory.

According to Austin (1962) to accomplish actions in everyday life entail employing the necessary words under the appropriate circumstances, that is, we are using appropriate words in appropriate time to perform certain actions in daily life, Austin proposed a distinction of communication acts:

(i) Locutionary act: "locutionary" which is roughly equivalent to uttering a sentence with a certain sense and reference to mean something.

(ii) Illocutionary act: "illocutionary" that is performing act in saying something. [9].

(iii) Perlocutionary act: "perlocutionary" that is bringing about something by saying something

When we perform a locutionary act, we are uttering a certain sentence with a certain sense, which is the meaning of the literal sense; illocutionary acts such as informing, ordering,warning, inviting, requesting, or complaining, refer to different types of function of language; perlocutionary acts mean what we bring about or achieve by saying something, that is, the effect of the illocution on the hearer. Originally, Austin used the term "speech act" to refer to an utterance and the "total situation in which the utterance is issued"[10]; now"speech act" is used to mean the same as "illocutionary act".

John Searle, developed the speech act theory at Oxford in the 1950's. He put forwards his main ideas in his earlier book Speech acts: an essay in the philosophy of language (1969) and his collection of articles under the title of Expression and Meaning (1979). Searle holds that utterances can not subject to true or false; they must meet some felicity conditions, under which words can be used to properly perform actions. He also classified speech acts according to their functions, including representatives, commissions, directives, declarations, and expressions[11].

when we are apologizing, greeting, initiating, refusing, complimenting, and complaining, we in fact perform speech acts at the same time. This paper will focus on the speech act of refusal based on the speech act theory, which is the theoretical basis of this research.

\section{Methodology}

\section{Research Questions}

It can be found from the introduction of previous studies that there are few researches have examined the speech act of refusal among Chinese college students from the perspective of gender difference. This paper will focus on this perspective and aim to answer the following questions: 
(1) What strategies are preferred by male and female students respectively when refusing others? What is the overall tendency?

(2) What are the differences between male and female college students when using refusal strategies?

(3) In which situation is the most obvious difference occurring?

\section{Subjects}

A Total of 100 Chinese college students participated in this study, including 50 males and 50 females. Among the 100 students, 50 are the students of Nanjing University of Finance and Economics, and the others are students from other universities. All subjects are aged from 18 to 23, and most of them are freshmen and sophomores in university, therefore, to some extent, they have similar social status and educational background.

\section{Questionnaire and Interview}

To get enough information and to ensure the objectivity of the survey, the study was carried out by means of questionnaire investigation and interview.

The questionnaire consists of two parts: basic information and questions. The "basic information" part requires subjects to fulfill their gender and age, which makes the cross-over analysis possible. The "questions" part has twelve questions, which represents twelve situations. It includes four stimulus types eliciting a refusal, that is, 4 requests, 2 invitations, 3 suggestions, and 3 offers. The following chart gives the information of the questionnaire.

There are three options for each question: (i) Refuse directly, (ii)Refuse directly and give the reasons, (iii)(Apologize), refuse indirectly and give the reasons. And the subjects are Chinese students, so the questionnaire for them is written in Chinese, then they can realize the questions and situations better.

Besides questionnaire investigation, interview was also conducted on a part of subjects to collect the specific strategies they use in certain situations, which helps the analysis of the difference between male and female students' refusal strategies.

\section{Data Collection}

The questionnaire was uploaded to SOJUMP, which is an online system of conducting questionnaire. Subjects can do the questionnaire on the system, then the system will collect the data of these questionnaires. It can help collecting the answers of subjects and analyzing the data that has been collected. The online system has received 100 answers sheets, including 50 female's and 50 male's answers, and all questions in the questionnaires were fulfilled.

\section{Data Analysis and Discussion}

In this chapter, the result of the investigation will be provided and an analysis will be carried out. In addition, owing to the different initiating acts, the difference between male and female students' refusal strategies in different situations of initiating act will be summarized.

\section{Refusal Strategy Use between Male and Female}

According to Beebe's classification of refusals, direct strategies and indirect strategies take the great portion (Beebe et al., 1987), and Seale (1975) holds that in the performances of refusal speech act, the rejecters may consciously avoid the direct refusal "no" to maintain a polite manner. Every question of the questionnaire has three options, including direct strategy, indirect strategy and a neutral strategy, therefore, an overall tendency of the selection of refusal strategy, and the difference between male and female students' selection can be reflected in the data of the survey.

table 1. The number of " $\mathrm{AB}>\mathrm{C}$ " and " $\mathrm{AB} \leqq \mathrm{C}$ "

\begin{tabular}{|l|l|l|}
\hline Options & Male & Female \\
\hline $\mathrm{AB}>\mathrm{C}$ & 18 & 12 \\
\hline $\mathrm{AB} \leqq \mathrm{C}$ & 32 & 38 \\
\hline Total Number & 50 & 50 \\
\hline
\end{tabular}


table 2. Total number and percentage of direct and indirect strategies used in overall situations

\begin{tabular}{|l|c|l|l|l|}
\hline \multirow{2}{*}{ Strategy } & Male & Percentage & Number & Percentage \\
\cline { 2 - 5 } & Number & $36 \%$ & 12 & $24 \%$ \\
\hline $\begin{array}{l}\text { Direct } \\
\text { Strategies }\end{array}$ & 18 & $64 \%$ & 38 & $76 \%$ \\
\hline $\begin{array}{l}\text { Indirect } \\
\text { Strategies }\end{array}$ & 32 & $100 \%$ & 50 & $100 \%$ \\
\hline Total Number & 50 & & & \\
\hline
\end{tabular}

The data in table 1 is collected according to the number of choosing the option A (Refuse directly), option B (Refuse directly and give the reason), and option C ((Apologize), refuse indirectly and give the reasons). We can see more male and female students prefer to an indirect and polite way when refuse others. In their answers, the number of $\mathrm{C}$ is more than the total number of $\mathrm{A}$ and B. Less students choose the direct way. In their selections, the total number of A and B is more than the number of $\mathrm{C}$. However, the differences between male and female can also be found. In the group " $\mathrm{AB}>\mathrm{C}$ ", males are more than females. By contrast, in the group " $\mathrm{AB}<\mathrm{C}$ ", females are more than males. On the basis of Figure 1, the total number and percentage of direct and indirect strategies used in overall situations can be worked out.

In table 2, it can be concluded that, in the males group, the direct strategies take the $36 \%$ of the total strategies, indirect strategies 64\%; In the female group, the direct strategies take the $24 \%$ of the total strategies, indirect strategies $76 \%$.

The results reveal that the two groups of subjects have some characteristics in common. They all tend to employ substantially more indirect strategies than direct ones. Although direct refusal is clear and effective in accomplishing the refusal, it threats others' face. Therefore, it is less adopted, especially in China's context, which emphasizes politeness and reciprocity. Besides, when the percentages of male and female are compared, it also can be found that there are more females than males prefer indirect strategies, which may reflect that female students are more indirect and polite than male students.

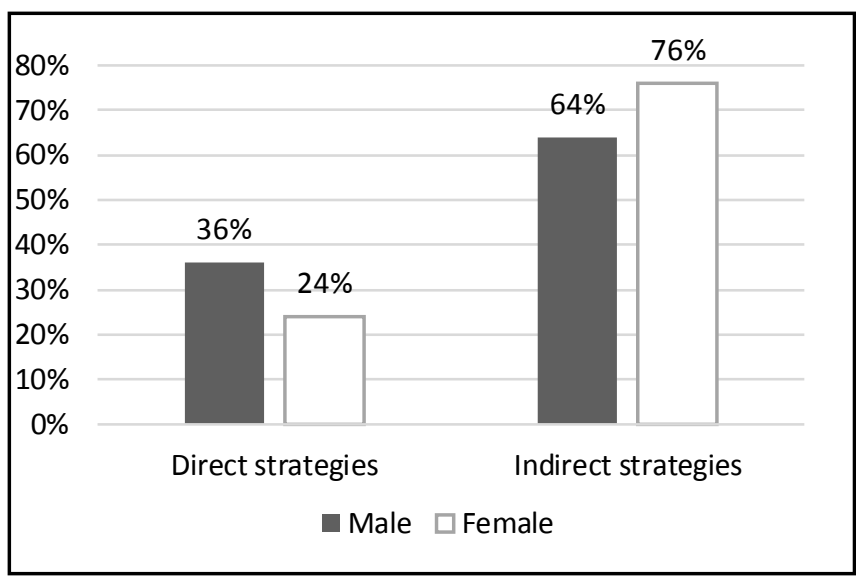

Figure 1. Total percentage of direct and indirect strategies used in overall situations

\section{Distribution of Refusal Strategy in Different Initiating Acts}

This part will focus on the frequency of refusal strategies according to the type of initiating speech acts. It provides examples and illustrates how the different initiating speech acts affect males and females on using refusal strategies.

Total Analysis 
table 3. Total percentage of direct and indirect strategies used in different initiating speech acts.

\begin{tabular}{|l|l|l|l|l|l|l|l|l|}
\hline \multirow{2}{*}{ Strategy } & \multicolumn{2}{l|}{ Request } & \multicolumn{2}{l|}{ Suggestion } & \multicolumn{2}{l|}{ Invitation } & \multicolumn{2}{l|}{ Offer } \\
\cline { 2 - 8 } & Male & Female & Male & Female & Male & Female & Male & Female \\
\hline Direct & 98 & 77 & 103 & 94 & 43 & 18 & 97 & 52 \\
Strategies & $49 \%$ & $38.5 \%$ & $68.7 \%$ & $62.7 \%$ & $43 \%$ & $18 \%$ & $64.7 \%$ & $34.7 \%$ \\
\hline Indirect & 102 & 123 & 47 & 56 & 57 & 82 & 53 & 98 \\
Strategies & $51 \%$ & $61.5 \%$ & $31.3 \%$ & $37.3 \%$ & $57 \%$ & $82 \%$ & $35.3 \%$ & $65.3 \%$ \\
\hline
\end{tabular}

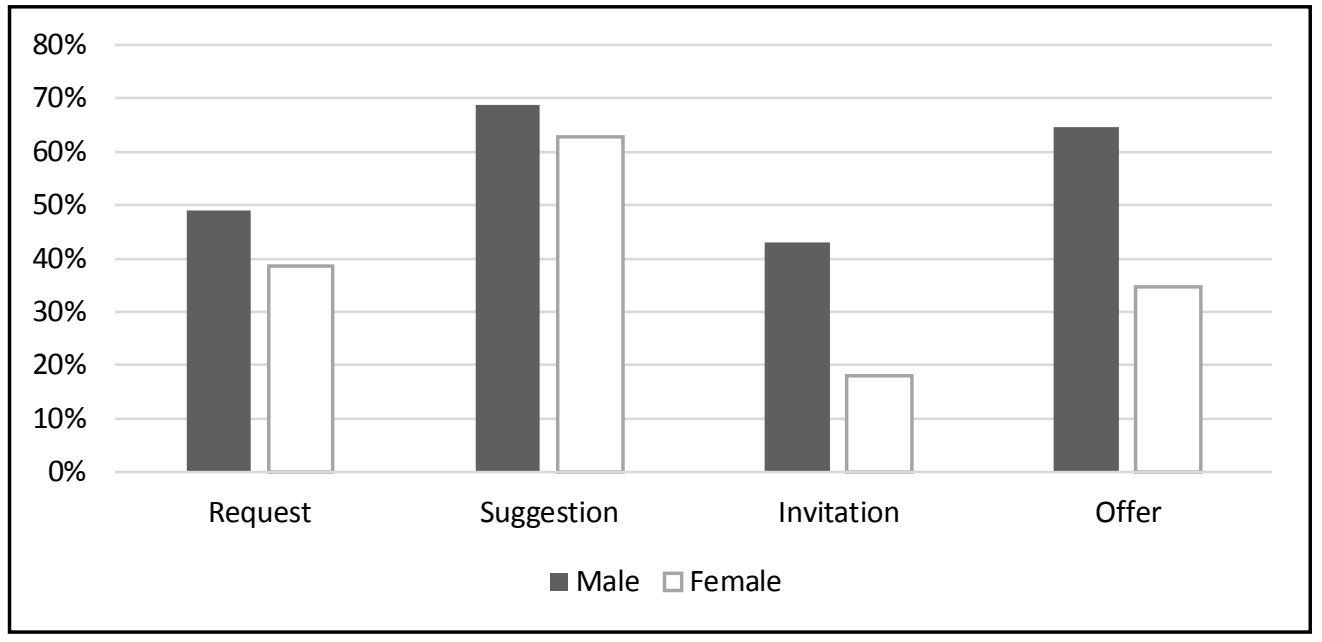

Figure 2. Direct strategies used according to different initiating speech acts

Some explanations are given at first. The number of the question of the four situations is different, so attention should be paid on the percentage instead of the specific number. Besides, the option A and B are regarded as direct strategies while the option $\mathrm{C}$ as indirect strategies.

To explore male and female students' refusal strategies in different situations, it is necessary to work out the percentage of direct and indirect strategies used in different initiating speech acts. table 3 indicates that female subjects tend to use more indirect refusal strategies in these four situations than male subjects; both male and female subjects use more direct strategies when refusing suggestion(males $68.7 \%$ and females $62.7 \%$ ); both male and female subjects use more indirect refusal strategies in refusing invitation(male $57 \%$ and female $82 \%$ ). Therefore, it can be concluded that female students are more polite and cooperative in different initiating speech acts than male students.

From Figure 2 we can see that both male and female students tend to be direct in refusing suggestion, but it is hard for them to refusing invitation. In addition, there is an obvious difference between male and female subjects when refusing offer, that is, a large part of male subjects choose direct strategies while a large part of female subjects choose indirect strategies $(64.7 \%$ of male choose direct way while $65.3 \%$ of female choose indirect way).

Analysis of Typical Examples

To further explain subjects' refusal strategies in different situations and answer the research questions scientifically and objectively, this part will provide a detailed analysis for the data of some questions in the questionnaire.

Refusing Request 
Question2 "Your good friend asks you to help him or her move to new house." in the questionnaire is selected as an example to be analyzed.

\section{table 4. Data of question2}

\begin{tabular}{|l|l|l|}
\hline Strategy & Male & Female \\
\hline Direct strategies & $26(52 \%)$ & $13(26 \%)$ \\
\hline Indirect strategies & $24(48 \%)$ & $37(74 \%)$ \\
\hline
\end{tabular}

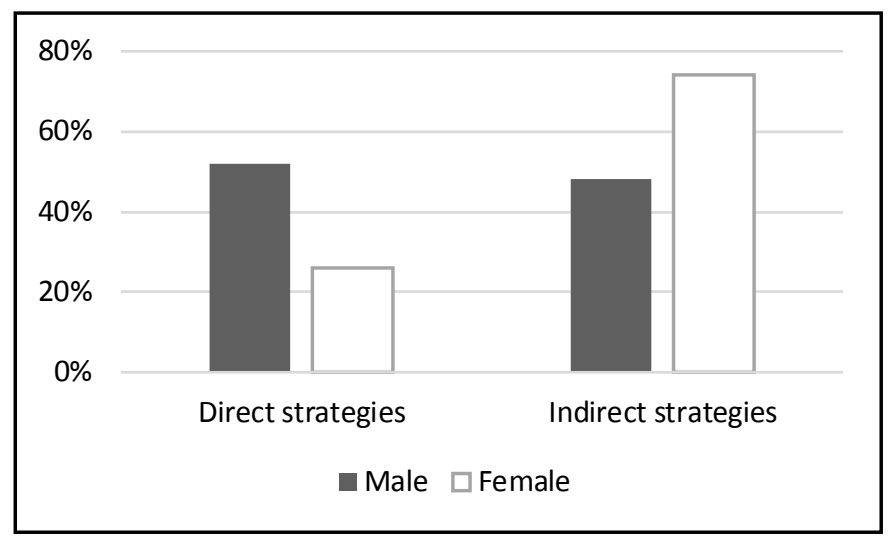

Figure 3. Data of question2

table 4 and Figure 3 show that, being viewed as a whole, the majority of the students choose the indirect and polite way, but there is still a difference between male and female students. There is no obvious tendency of male students' refusal strategies, while most female students prefer indirect strategies(74\%). It indicates that in the situation when face a request from a friend, more females choose to refuse indirectly and politely. Compared with female students, male students are more likely to refuse a request in a direct way.

In addition, some answers in the oral interview were recorded, and there are two students' answers for question2:

Sorry, I'm afraid that I have no spare time, for I'm going to attend a test in several days. (female)

I can't go to help you, because I will go out with my roommates. (male)

From the female student's answer, we can know how she conducts the indirect strategy. She apologizes at first, then refuses indirectly and explains the reason. However, although the male student also explain the reason, he refuses others directly by saying "I can't go". It can be found that female students consider much about others' feelings when refusing a request, and they are more polite and cooperative, while male students may want to solve questions quickly and effectively.

Refusing Offer

Question 11 "A friend visits your house, but she suddenly breaks a vase in living room. She insists to pay for it." is a typical situation of refusing offer, and it reflects the difference between male and female students' refusal strategies apparently.

Table 5. Data of "question 11"

\begin{tabular}{|l|l|l|}
\hline Strategy & Male & Female \\
\hline Direct strategies & $39(78 \%)$ & $25(50 \%)$ \\
\hline Indirect strategies & $11(22 \%)$ & $25(50 \%)$ \\
\hline
\end{tabular}




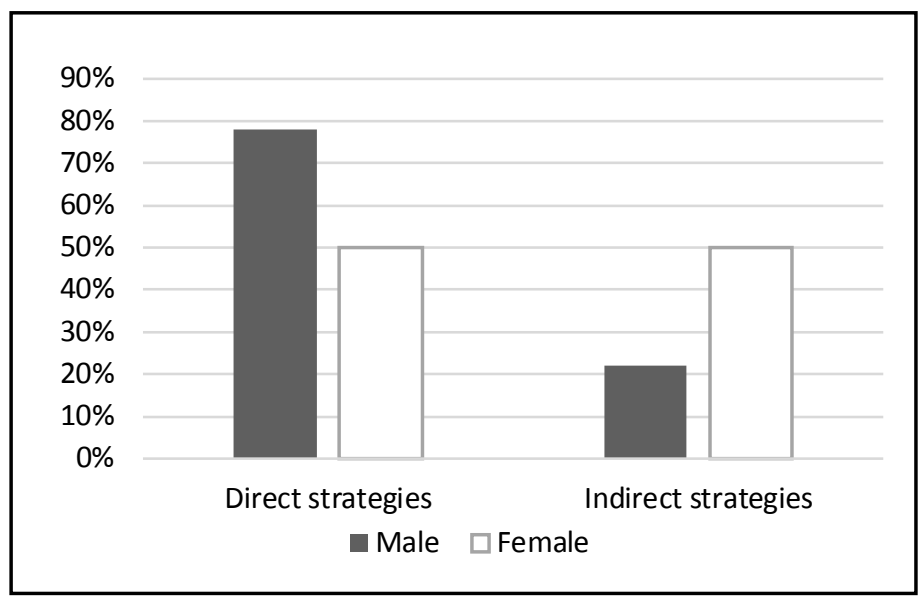

Figure 4. Data of question11

In the situation of question 11, the status of the rejecter is higher than the rejectee, therefore the number of people who choose direct refusal strategy relatively increased.

However, Table 5 also indicates that male and female students are different in refusing the offer from a friend. A large part of male subjects choose direct strategies( $78 \%)$ while half of the female students use indirect strategies $(50 \%)$. It shows that female tend to be polite and cooperative even though in the conversation that their status is higher than others'. There are also two answers of question 11 from the interview of students:

It doesn't matter. It is not a expensive thing, and take it easy. (female)

No, you needn't to do that. (male)

From these two typical answer, we can see that female students pay much attention to others' feeling and they try to comfort others, while male students seem to very direct and uncooperative. According to the interview, some male students said that it is good for others to hear that they need not to pay money, so the rejecters should refuse directly. Some male students only want to make their attitude clear and solve the problem effectively, and sometimes they do not consider much about others' thought.

\section{Summary of the Analysis}

From above analysis, it can be concluded that both of male and female students use substantially more indirect strategies than direct strategies in most cases. Although indirect strategies are preferred by these two groups, there still exists difference between male and female subjects in terms of the probability of indirectness. Female students' refusals tend to be more gentle and indirect than those of male students. Female students like to explain reasons, and they prefer to use detailed and specific response instead of a direct "no". By contrast, male students' refusals tend to be direct, brief and even blunt.

Students' refusal strategies in four different situations were also analyzed. Male and female students' tendency of refusal strategies are similar in refusing request and invitation, but differences are appeared in refusing suggestions and offers. Direct strategies are most frequently used in refusing suggestion by male and female students. Besides, male and female students have different tendency in refusing offers.

From the total percentage of direct and indirect strategies used according to different initiating speech acts, female subjects use more indirect refusal strategies than male subjects do when refusing others' invitations, requests, suggestions and offers. And female students also tend to use more hedges and they tend to be more vague when refusing others.

\section{Conclusion}

This paper aims at exploring the gender differences in speech acts of refusal of Chinese college students. The second part has introduced some related previous studies on refusal and gender 
difference, which shows that there are few studies on linguistic gender differences of Chinese college students. That is why this paper focuses on this topic. Refusal is a kind of speech act, so Speech Act Theory of Austin is the theoretical basis of this paper.

The research used qualitative study and quantitative study. It was conducted on 100 college students by using questionnaire investigation and interview. And the data was collected by an online system.

The results indicate that both of male and female students tend to use indirect refusal strategies, but they have significant difference. Female students are more indirect and polite, and they tend to give many explanations and specific things when refusing others. Male and female students also show differences when they refuse others in terms of different initiating speech act. The most obvious difference appeared when refusing offers. Most male students use direct strategies while most female students use indirect strategies. Besides, the tendency of both male and female students' refusal strategies changed when refusing suggestions. Direct strategies are preferred by them in this situation. In addition, from the answers of interview we can find that female students usually consider much about others' feelings and thought, and they often try to comfort others and avoid hurting others' face.

This paper may help male and female to know more about themselves, and they also need to realize the choices and habits of others in different gender, then cross-gender communication can be proceeded successfully.

\section{Limitation and Suggestion}

There are still some problems in this paper. Firstly, in consideration of subjects' attitude and limited time, there is no question type of completion or supplementation, and the specific situation of their refusals can not be taken into consideration. Secondly, the number of the questions in questionnaire is limited, which may influence the scientificity of the result. Thirdly, only two typical specific examples are analyzed in this paper, which may not enough to explain the result clearly.

Studies on gender difference and refusal in future need to consider some social factors, such as social status and power distance. And gender differences on other kinds of speech act also need to be further studied.

\section{References}

[1] Beebe, L., T. Takahashi, and R. Uliss-Weltz. Pragmatic Transfer in ESL Refusal[C].In Scarcella, E. Anderson \& S. Krashen, eds. On the Development of Communicative Competence in a Second Language. New York: Newbury House, 1990:22-73.

[2] Liao, C.C. and Bresnahan, M.J., A Contrastive pragmatic study on American English and Mandarin Refusal Strategies[J]. Lang. Sci.,1996:703-727.

[3] Gacia, Carmen. Refusing an Invitation: A Case Study of Peruvian Style[J]. Hispanic Linguistics, 1992(5):207-243.

[4] Lakoff, Robin. Language and Woman's Place[M]. New York: Harper and Row, 1975.

[5] Maltz, Daniel N. and Ruth A. Borker. A Cultural Approach to Male-Female Miscommunication: Language and Social Identity[M]. Ed. John J. Gumperz.Cambridge: Cambridge UP, 1982.

[6] Tannen, Deborah,ed. Gender and Conversational Interaction[M]. New York: Oxford UP, 1990.

[7] Crawford, Mary. Gender and Humor in Social Context[J]. Journal of pragmatics, 2003(35):1413-1430.

[8] Zhao Yuanren. A Research on Modern Wu Dialect[M]. Beijing: Commercial Press, 2011.

[9] Levinson, S.C. Pragmatics[M]. Beijing: Foreign Language Teaching and Research Press, 2001.

[10] Austin,J.L. How to Do Things with Words[M]. Oxford: The Clarendon Press, 1962.

[11] Searle,J. Indirect Speech Acts[C]. Syntax and Semantics, New York:Academic Press, 1975: 59-82. 


\section{Appendix}

\section{Questionnaire}

This questionnaire is for a survey about the speech act of refusal in daily life. Please read the following situations and try to choose the refusal strategy that you prefer. Your choice will contribute to the result of the survey. Thank you for your cooperation!

\section{Your gender: A. Male B.Female}

1. A teacher asks you to stay after school to help him receive new students.
A. Refuse directly
B. Refuse directly and give the reasons
C. Apologize, refuse indirectly and give the reasons

2. Your good friend asks you to help him or her move to new house.
A. Refuse directly
B. Refuse directly and give the reasons
C. Apologize, refuse indirectly and give the reasons

3. Before a test, a classmate usually absent from class asks you to lend your notebook to him.
A. Refuse directly
B. Refuse directly and give the reasons
C. Apologize, refuse indirectly and give the reasons

4. Your brother asks you to lend 500 yuan to him.
A. Refuse directly
B. Refuse directly and give the reasons
C. Apologize, refuse indirectly and give the reasons

5. Your classmate suggests you change your hair style.
A. Refuse directly
B. Refuse directly and give the reasons
C. Refuse indirectly and give the reasons
6. You always surf on internet in summer holidays, then your parents suggest you do some sports.
A. Refuse directly
B. Refuse directly and give the reasons
C. Apologize, refuse indirectly and give the reasons

7. You have a part-time job in a school. A student suggests you change your teaching method, but you do not agree with him.
A. Refuse directly
B. Refuse directly and give the reasons
C. Apologize, refuse indirectly and give the reasons

8. An old classmate invites you to attend her wedding.
A. Refuse directly
B. Refuse directly and give the reasons
C. Apologize, refuse indirectly and give the reasons

9. During summer holiday, your aunt invites you to her house, but you do not want to go there.
A. Refuse directly
B. Refuse directly and give the reasons
C. Apologize, refuse indirectly and give the reasons

10. You are watching TV at a friend's home. She offers you a snack, but you do not want to eat it because you want to keep fit.
A. Refuse directly
B. Refuse directly and give the reasons
C. Refuse indirectly and give the reasons

11. A friend visits your house, but she suddenly breaks a vase in living room. She insists on paying for it.
A. Refuse directly
B. Refuse directly and give the reasons
C. Refuse indirectly and give the reasons

12. Your professor offers you a part-time job, but you are not able to take it for some reason.
A. Refuse directly
B. Refuse directly and give the reasons
C. Apologize, refuse indirectly and give the reasons 